\title{
Hungary to rationalize its university system
}

Budapest. A new committee has been set up by the Hungarian government to recommend which of the country's 25 state universities should be allowed to retain their university status, and which should be given the right to award the newly established $\mathrm{PhD}$ degrees. The committee was established under a law passed last summer to restructure the Hungarian university system in line with the country's post-communist policies.

The new law requires every full university to have at least two faculties. Many at present have only one speciality, and the committee, made up of academics from universities and research institutes, will recommend which institutions should merge and which should lose their university status. A maximum of eight major universities are likely to emerge from this restructuring.

The law has also introduced for the first time a three-year $\mathrm{PhD}$ degree, to be conferred by universities. The new $\mathrm{PhD}$ programmes, which began last September, require students to attend formal lecture programmes and prepare a thesis. The committee will determine which departments and faculties will be allowed to participate in the programmes.

The new $\mathrm{PhD}$ will eventually take the place of the less structured 'candidate of science' degree, still being conferred by the State Committee of Qualification, a body connected to (but not controlled by)

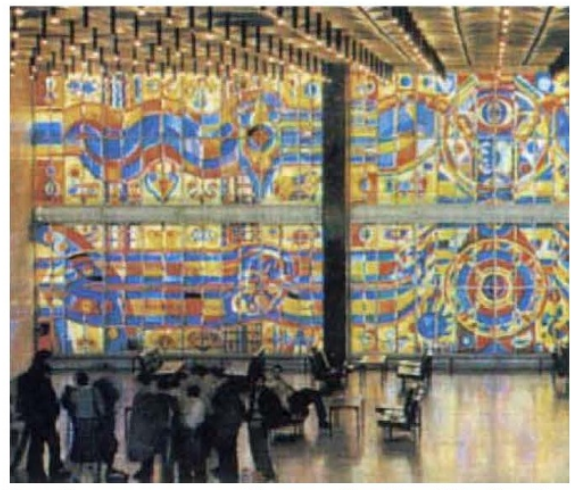

Due for a merger: Semmelweiss Medical University in Budapest.

the Hungarian Academy of Sciences.

While the Candidate of Science degree has been limited to a maximum of 150 students a year, the new $\mathrm{PhD}$ programme has already enrolled more than 2,000 students. The Ministry of Education has provided Ft314 million (US\$3.16 million) for the programme this year.

Arpad Csurgay, a professor of informatics at the Technical University in Budapest, admits that the immediate popularity of the new degree is partly a symptom of the poor employment prospects for graduates in Hungary's struggling economy. "It's the best way for young people to postpone the frightening moment of looking for a job when there are so few opportunities," he says.
The higher education law proposes to raise the number of university students in Hungary, which has one of the lowest levels of participation in higher education in Europe, from 100,000 to 150,000 over the next six years. József Hámori, chairman of the University Rectors Conference, hopes that most of the increase will be confined to the non-university higher education sector. At the same time he wants to raise the quality of teaching universities "because we need to increase the quality, not just the quantity, of our students".

Further reforms are expected, and a second higher education law is being drafted by the newly established Council of Higher Education and Science, a body made up of representatives from academic institutions, government and other interested parties, such as industry and local government. A bill based on the committee's conclusions is expected to be submitted to parliament by the end of the year.

This second law will determine the details of the development of higher education over the next decade by, for example, specifying the number of student places to be provided in technical colleges and in universities.

It will also recommend what proportion of the country's gross national product should be allocated to science: the communist state put nearly 2 per cent into research, but the figure has now dropped to 0.8 per cent.

Alison Abbott

\section{Russian newspaper yields to the lure of pseudoscience}

Moscow. Serious science journalism in Russia suffered a blow last month when the daily newspaper Izvestiya - which has up to now rigorously denounced pseudoscience and refused to give the same prominence as other publications to activities such as parapsychology - published a feature about a tractor mechanic who claims to have invented a time machine.

Almost every news programme on Russian television now ends with an astrological forecast when viewers are advised about their business activities, health care, family matters, sexual behaviour and so on. Millions of Russians, brought up to look on television as the source of state-approved information, appear to be influenced by these instructions.

Parapsychologists can be seen on the screen virtually every day. Even the surprise success of Vladimir Zhirinovsky in the recent elections has been widely attributed to television appearances on his behalf by $\mathrm{Dr}$ Kashpirovsky, a well-known psychotherapist (and, apparently, hypnotist) who claims that practically all diseases can be cured by watching his television programmes

The Izvestiva article marks an editorial shift in a newspaper that had previously avoided this trend. It described how Yuri Kunyansky, 50, claims to have overcome the problems of relativity to construct his time machine.

Kunyansky's career has had little connection with solving the problems of space and time; his previous activities include repairing tractors, writing an essay on "resonance in sex" and maintaining machinery at a power station near Moscow.

The report in Izvestiya claimed that Kunyansky has been invited by the Russian Academy of Sciences to participate in a seminar headed by Aleksandr Prokhorov, one of the few Russian Nobel prizewinners. It also said that the AGAT company, part of the Russian Space Agency, has agreed to build Kunyansky's machine. Oleg Budakov, a spokesman for AGAT, was quoted as saying that he hoped resources for the machine would be provided by the government not later than 1995.

Despite such signs of support, Kunyansky is apparently not satisfied with the way things are going. The newspaper quotes him as saying that a properly functioning time machine is still a long way off, as the current design will still take 20 minutes to travel a hundred years in either direction.

But the newspaper itself seems to have had its doubts. In a subsequent issue, it published an article by the same journalist, Sergei Leskov, saying that the Russian Academy considers Kunyansky's theory to be naive, and that nothing should be read into his attendance at the academy's meeting.

Izvestiya has also published a letter from Academician Vitaly Ginzburg criticizing it for deceiving readers about the possibility of constructing time machines.

Ginzburg wrote that President Boris Yeltsin's office, which was reported to have expressed interest in Kunyansky's project, lacks the expertise to judge such matters. $\mathrm{He}$ also pointed out that, despite earlier reports, the inventor will not be allowed to present a report at Prokhorov's seminar at the academy. 